\title{
A Multiple Objective NSGA-II-based Optimization Program (MONOP) and Its Application to ReaxFF Reactive Force Field for 2,4,6-Trinitrotoluene Diffusion in the Aqueous Phase
}

\author{
Guan Zhang, Jin Li, Zongkuan Liu*
}

School of Human Settlement and Civil Engineering, Xi'an Jiaotong University, Xi'an, 710049, China

*E-mail: zkliu@xjtu.edu.cn

\section{CONTENTS:}

1. The change of the ReaxFF reactive force field Van der Waals parameters after MONOP optimization

2. Discussion on selection of basic parameters 
1. The change of the ReaxFF reactive force field Van der Waals parameters after MONOP optimization

\begin{tabular}{|c|c|c|c|c|}
\hline parameter & atom (pair) & CHON-2017_weak & TNT/water & $\operatorname{diff} \%$ \\
\hline \multirow{4}{*}{$\mathrm{r}_{\mathrm{vdw}}$ : single atom parameters } & $\mathrm{C}$ & 2.0270 & 2.3310 & 15.00 \\
\hline & $\mathrm{H}$ & 1.6791 & 1.8993 & 13.11 \\
\hline & $\mathrm{O}$ & 2.3396 & 2.1432 & -8.39 \\
\hline & $\mathrm{N}$ & 1.9690 & 1.9207 & -2.45 \\
\hline \multirow{4}{*}{$\varepsilon:$ single atom parameters } & $\mathrm{C}$ & 0.1113 & 0.1124 & 0.99 \\
\hline & $\mathrm{H}$ & 0.0709 & 0.0702 & -0.99 \\
\hline & $\mathrm{O}$ & 0.1000 & 0.0992 & -0.80 \\
\hline & $\mathrm{N}$ & 0.1513 & 0.1498 & -0.99 \\
\hline \multirow{4}{*}{$\alpha$ : single atom parameters } & $\mathrm{C}$ & 8.7696 & 8.7502 & -0.22 \\
\hline & $\mathrm{H}$ & 8.3519 & 8.2694 & -0.99 \\
\hline & $\mathrm{O}$ & 9.3187 & 9.2786 & -0.43 \\
\hline & $\mathrm{N}$ & 8.8823 & 8.9152 & 0.37 \\
\hline \multirow{4}{*}{$\gamma_{\mathrm{w}}$ : single atom parameters } & $\mathrm{C}$ & 4.5389 & 4.5538 & 0.33 \\
\hline & $\mathrm{H}$ & 39.1732 & 39.4902 & 0.81 \\
\hline & $\mathrm{O}$ & 12.5083 & 12.5186 & 0.08 \\
\hline & $\mathrm{N}$ & 9.1048 & 9.1958 & 1.00 \\
\hline \multirow{6}{*}{$\mathrm{D}(\mathrm{ij})$ : off-diagonal parameters } & $\mathrm{C}-\mathrm{H}$ & 0.1165 & 0.1156 & -0.77 \\
\hline & $\mathrm{C}-\mathrm{O}$ & 0.0697 & 0.0690 & -1.00 \\
\hline & $\mathrm{C}-\mathrm{N}$ & 0.1261 & 0.1267 & 0.48 \\
\hline & $\mathrm{H}-\mathrm{O}$ & 0.0283 & 0.0286 & 1.06 \\
\hline & $\mathrm{H}-\mathrm{N}$ & 0.1154 & 0.1143 & -0.95 \\
\hline & $\mathrm{O}-\mathrm{N}$ & 0.1819 & 0.1836 & 0.93 \\
\hline \multirow{6}{*}{$r_{\mathrm{vdw}}(\mathrm{ij})$ : off-diagonal parameters } & $\mathrm{C}-\mathrm{H}$ & 1.3851 & 1.1774 & -15.00 \\
\hline & $\mathrm{C}-\mathrm{O}$ & 2.0716 & 1.7610 & -14.99 \\
\hline & $\mathrm{C}-\mathrm{N}$ & 1.9631 & 1.8861 & -3.92 \\
\hline & $\mathrm{H}-\mathrm{O}$ & 1.2853 & 1.0925 & -15.00 \\
\hline & $\mathrm{H}-\mathrm{N}$ & 1.4616 & 1.5151 & 3.66 \\
\hline & $\mathrm{O}-\mathrm{N}$ & 1.8000 & 1.5971 & -11.27 \\
\hline \multirow{6}{*}{$\alpha(\mathrm{ij}):$ off-diagonal parameters } & $\mathrm{C}-\mathrm{H}$ & 9.9415 & 9.8668 & -0.75 \\
\hline & $\mathrm{C}-\mathrm{O}$ & 9.6540 & 9.7499 & 0.99 \\
\hline & $\mathrm{C}-\mathrm{N}$ & 9.7006 & 9.6243 & -0.79 \\
\hline & $\mathrm{H}-\mathrm{O}$ & 10.9173 & 10.8081 & -1.00 \\
\hline & $\mathrm{H}-\mathrm{N}$ & 9.1198 & 9.1467 & 0.29 \\
\hline & $\mathrm{O}-\mathrm{N}$ & 9.4170 & 9.4876 & 0.75 \\
\hline
\end{tabular}

Note: diff indicates the value of the relative error. 
2. Discussion on selection of basic parameters

Compared with earlier widely used $\mathrm{C} / \mathrm{H} / \mathrm{O} / \mathrm{N}$ force field parameters, the protein reactive force field (protein-2013), CHON-2017_weak force field parameters have a more accurate description of the weak interaction of functionalized hydrocarbon/water molecules in the condensed phase. Especially for water density, the CHON-2017_weak (0.99) can perform much better than the protein-2013 $(0.87)^{1}$. The TNT/water system we studied needs accurate description of the water phase and TNT crystal. The CHON-2017_weak force field parameters can ensure good performance in the water phase first. Therefore, we do not need to add the hydrogen bond parameters into the optimization range, so as to reduce the disturbance to the original parameters. Accordingly, in the optimization process, we only need to optimize the relevant parameters with the experimental value of the TNT crystal density as the objective, while ensuring that the new parameters change little in the description of the water phase compared with the basic parameters as much as possible. In conclusion, the CHON-2017_weak force field parameters are reasonable as the basic parameters for the optimization of the $\mathrm{TNT} /$ water system.

\section{REFERENCES}

(1) Zhang, W.; Van Duin, A. C., Improvement of the ReaxFF description for functionalized hydrocarbon/water weak interactions in the condensed phase. The Journal of Physical Chemistry B 2018, 122, (14), 4083-4092. 